\title{
Francisco Zúñiga Díaz: tres facetas de un hombre de letras
}

\author{
Hiram Castro Carvajal \\ Colegio Seminario \\ San José, Costa Rica
}

\section{Resumen}

En este artículo sobre la obra del escritor costarricense Francisco Zúñiga Díaz (1931-1997), se tratarán tres aspectos de su obra como hombre de letras: investigador, humorista y novelista.

Palabras claves: Francisco Zúñiga Díaz, literatura costarricense, talleres literarios

Abstract:

In this article about Costa Rican writer Francisco Zúñiga Díaz (1931-1997), three subjects related to his literary work will be studied: researcher, humorist, and novelist.

Keywords: Francisco Zúñiga Díaz, Costa Rican literature, literary workshops

\section{EL INVESTIGADOR}

Ahora, el escritor nos sorprende con una obra que me atrevo a calificar de monumental. Juan Frutos Verdesia 


\section{EI maestro Francisco}

$\mathbf{Z}$ úñiga no hubiera podido llegar a ser director de un taller literario si el gusanillo de la docencia no estuviese en él. Un interés parecido a la docencia radica en todo investigador que desea difundir su obra, pues lo investigado se convierte en beneficio para los demás.

Sus dos grandes trabajos investigativos atestiguan ese anhelo de enseñar, de transmitir conocimiento, de compartir un saber sobre nuestras letras que suele ser menospreciado, ya no por el público y lector general, sino hasta por el mismo ámbito académico. Su queja hacia este sector solía referirse a que suele estar más enterado de los best-sellers y grandes novedades de otras latitudes, antes de percatarse de lo que se hace en nuestro patio. Conceptos que no decía en público, que se callaba demasiado bien, por su forma de ser. $\mathrm{Su}$ naturaleza diplomática, que llaman.

Como sonetista, resulta natural su interés en la manifestación que esta forma métrica ha tenido en el país. Consciente del abandono en el cual el lector suele tener a la poesía costarricense, la antología $E l$ soneto en la poesía costarricense (1979) pretende ser una vista general del quehacer poético nacional, enfocado en el soneto. La dedicatoria del volumen al autor de Alas en fuga, Julián Marchena, es toda una carta de intenciones, muy a su manera.

Autores olvidados y modernos, sonetos tradicionales y escandalosos conviven en sus trescientas páginas, donde se pasa revista a casi setenta autores, un auténtico ¿quién es quién? de poetas nacionales. A sus páginas son convocados, desde Pío Víquez, Moisés Vincenzi, José Basileo Acuña y Napoleón Quesada, hasta Isaac Felipe Azofeifa, Laureano Albán, Marco Aguilar y Mario Picado.

Mención aparte merece el estudio introductorio. Por su brevedad, y la humildad de Zúñiga, se comprende que aparezca designado como una nota introductoria. Sin embargo, y a pesar de sus quince páginas, notas incluidas, constituye uno de los textos más lúcidos y documentados sobre la historia y estructura del soneto en general, además del paso de la forma desde sus orígenes italianos hasta la actualidad costarricense, teniendo como filtro el aporte español al soneto:

La configuración del soneto fue tomada por Da Lentini de los elementos estróficos que se usaban en Sicilia y del ritmo de las composiciones de su tiempo. Su tarea se centró en darles una disposición distinta con un carácter única y meramente poético. De elaboración y método, en lo básico.

De ahí que no es sino Guido Gunezelli quien contribuye a unificar la forma, la cual se manifestaba con las ligerezas del descubrimiento de una elaboración novedosa, por lo suscinta y por el tono no tan elevado de las formas predecesoras.

De un soneto de construcción maciza se entra ya en la experimentación, con temas e imágenes, recogiendo efectos y esbozando un giro de novedades, ajenos a la inflexibilidad 
de primitiva factura del soneto concebido por Da Lentini. (Zúñiga, 1979 p.10-11)

Quizá el único lunar de dicho estudio es que omite referirse a la forma del soneto británico, pero es comprensible, si tenemos en cuenta que la forma de tres cuartetos y dístico del soneto inglés no se practica en nuestra poesía.

Como suele pasar con muchas ediciones en nuestro país, y a pesar de ser una publicación a cargo de la Editorial de la Universidad de Costa Rica, el levantado de texto presenta algunos errores en cuanto a la consignación de fechas o datos biográficos, así como en la digitación de unos cuantos poemas. Zúñiga, al igual que muchos intelectuales costarricenses, se quejaba de la chapucería de las publicaciones en este país, como lo han hecho personas de la talla de Néstor Mourelo y otras voces perdidas en el desierto.

A pesar de estos galimatías, sigue siendo una obra obligatoria de consulta, si consideramos el enorme esfuerzo por la búsqueda, recolección, lectura y material seleccionado por Zúñiga para este trabajo. Solo intelectuales como Carlos Francisco Monge, Álvaro Quesada o Luis Gustavo Lobo quedan para trabajos de tales dimensiones y, lamentablemente, a Quesada lo hemos perdido hace ya más de diez años. Lo que hubiera podido esperarse de una investigación colegiada entre Zúñiga y Quesada solo puede inflamar nuestras más extravagantes fantasías. Sobre este gran esfuerzo de investigación, el periodista Carlos Morales afirma:
La idea de reunir la producción poética costarricense en su especialidad del soneto, constituye un buen aporte al conocimiento de nuestra literatura y es un esfuerzo encomiable que contribuye en mucho a determinar los alcances y las limitaciones de nuestra lira.

Como escritor que era, Zúñiga comprende a sus colegas. Resultaba muy natural, pues, que en algún momento emprendiera un proyecto de carácter biográfico. La gran mayoría de biografías sobre escritores son emprendidas por académicos, intelectuales, pero no por poetas o novelistas.

Talvez el ego de muchos escritores no permita que su ojo poético se desvíe hacia otra rara avis. Afortunadamente, no es el caso de Zúñiga. Todos quienes lo conocimos recuperamos su imago por medio de una sencilla palabra, sencilla como él mismo: humildad.

La biografía de escritores, realizada por un escritor, suele ser poco común, al menos en nuestro contexto actual. Habría que devolverse al romántico siglo XIX, y contemplar las miles de páginas vertidas por Berlioz, Wagner, Coleridge, Byron, Shelley, Goethe y culminando con Stefan Zweig, vate a caballo entre dos siglos. Quizá los proyectos que más valgan la pena, desde esta perspectiva, son el texto introductorio de Rubén Darío a la traducción en castellano de los poemas completos de Edgar Allan Poe, y la poética biografíaantología que preparó Julio Cortázar: Imagen de John Keats (1952). 
Su obra capital en su faceta de investigador la constituye la valiosa compilación Carlos Luis Sáenz: El escritor, el educador y el revolucionario (1991). Este libro se justifica, inicialmente, por motivos personales. Zúñiga estaba casado con Elsa María Sáenz Ferreto, hija de Carlos Luis Sáenz y Adela Ferreto. La íntima relación familiar facilitó la recolección de tanto material biográfico y literario totalmente inédito, como casi nunca puede lograrse con ningún autor.

El estudio introductorio abarca el centenar de páginas, tras el cual se suceden seiscientas páginas con todos los textos poéticos sueltos que escribiera Sáenz, incluyendo el diario que escribió durante su estadía en la cárcel. Este es, quizá, el texto más valioso y sorprendente de la compilación, ya que incluye dibujos del autor, y por su profundidad humana acaso sobrepase un texto tan meritorio como De profundis, o Balada de la Cárcel de Reading, de Óscar Wilde. Las observaciones de Sáenz sobre su detención y su estancia en el presidio, por razones políticas e ideológicas, son de lo más esclarecedor que se haya escrito por la pluma de un intelectual costarricense.

Debido a las grandes dimensiones de la investigación, y como la edición salió de su propio peculio, hubo que abaratar costos. La editorial Ipeca, en Barrio La Cruz, publicó la obra en un rústico papel periódico. Hoy en día, se trata de una de las grandes investigaciones sobre nuestra literatura, pero resulta prácticamente imposible de conseguir. Queda como obligación, para con Zúñiga y la historiografía literaria costarricense, que una nueva edición de la obra vea la luz.
Sobre la investigación, desde un plano más personal, nos habla la nieta de Carlos Luis, la poeta Li Sáenz:

Este libro es mi amparo, mi raíz, mi hilo hacia lo que nos representa como familia y entonces estoy con ellos, con ustedes, con todos, iqueriéndolos! Un libro no es un libro me dijo alguien alguna vez, y de veras puede ser tantas otras cosas, tantos otros símbolos y lenguajes, tantas otras formas de encuentro o desencuentro con este simple camino de saber ¿qué somos? ¿a dónde vamos? ¿vamos o venimos?

Este acercamiento no puede concluir sin hacer referencia a uno de los proyectos más apreciados por Zúñiga, pero que no pudo concretarse. Historia del humor en Costa Rica es el gran libro jamás escrito por Zúñiga Díaz. Varias veces compartió ese deseo con algunos otros miembros del Taller del Instituto Nacional de Seguros, como el poeta Cristián Marcelo Sánchez y el investigador Luis Gustavo Lobo. Era un tema que solía salir de vez en cuando, ya fuera en las tertulias de la Casona del INS o en la sala de su casa en Barrio México. Sin embargo, sus constantes preocupaciones personales, sus problemas de salud y la edición de sus últimos libros nunca le dieron el espacio suficiente para la elaboración de una investigación de tan gran envergadura.

Mirando sus dos grandes investigaciones sobre el soneto costarricense y la figura de Carlos Luis Sáenz, no nos cabe duda de que habría sido un trabajo como no se ha visto en nuestra historiografía literaria, al menos desde Abelardo Bonilla Baldares. Pero en la 
vida, el espacio que no es ocupado por un elemento, no tarda en ser llenado por otro.

Zúñiga no pudo escribir su investigación sobre el humor en Costa Rica, pero para su libro La encerrona de la Chupeta y otros desbarajustes (1996), el poeta Joaquín Garro, sonetista y miembro del Café Cultural del INS, escribe un prólogo brillante, en el cual le da su justo sitio de honor dentro de la literatura humorística costarricense.

\section{EL HUMORISTA}

\section{El extraño caso de Chico Zúñiga y T. Joroba}

Tutto nel mundo é burla

L'uom é nato burlone.

Ma ride ben chi ride

La risata final.

Arrigo Boito y Giuseppe Verdi, Falstaff

El humor era un elemento muy presente en la obra literaria de Zúñiga Díaz. Aunque el humor, el cinismo y la crítica siempre le permitieron sentirse a sus anchas, Zúñiga quiso crear una trinchera desde la cual el lindero de personalidad no le creara ningún problema o complejo de inhibición. Y así, en 1962, cual Dr. Jekyll, con el brebaje de la ironía, el cinismo y el doble sentido, nace su alter ego, su otro yo, un genio maligno, cuya única función es recordarle al lector que no es tan importante como para tomarse siempre en serio.

Desde su nombre, T. Joroba, la más pura de las imágenes lezamianas de Zúñiga, fue concebido para generar desconcierto, zozobra, creerse engañado - y creerlo bien - pues todos sus poemas son una trampa, arenas movedizas, un agujero negro que todo lo consume. Al final, como el cuento de la lechera, toda vanidad se vuelve humo y solo queda la risa, pues es mejor reír que llorar.

Su primera incursión en la vida pública de tan curioso y escurridizo personaje data de 1975, cuando ingresa al elenco del periódico Libertad. Al inicio, se introduce todo serio y modosito, con un poema en honor a Adolfo Herrera García... Pero luego, se desata, y se liberan el viento del oeste, el demonio de Tasmania y todas las plagas de Egipto juntas.

Mientras estuvo causando problemas en dicho periódico, hasta su salida en 1985 motivo de fiesta nacional para los demás miembros del rotativo - el recuento de los daños dejó varios poemas y un triunvirato maligno. T. Joroba, y otros calaveras de similar calaña como Hugo Díaz y Óscar Sierra, fueron conocidos como La pluma sonriente. El primer atentado terrorista de tan sospechoso grupo fue un pernicioso y suculento libro de sonetos y poemas varios.

No hay ninguna coincidencia ni casualidad en el hecho de que el apellido de este escurridizo personaje sea Joroba, mientras la publicación de su primer libro, Sonetos de amor en bicicleta (1977) aparezca bajo el sello Ediciones Dromedario. Hasta en esos detalles se deja ver la malicia malintencionada de su autor. Su cómplice, Hugo Díaz, perpetró los dibujos internos y la portada.

No hay tema que para T. Joroba sea prohibido: para él, todos son demasiado humanos, ya sean héroes griegos o patriarcas 
israelíes. Y si aún están escépticos, que nos lo digan Damocles y Moisés:

Mas al fin de donar para la historia Una frase colorida, el buen Dionisio, Colocóle en el trono adventicio Una espada colgante en fino hilo. Consecuencia: Damocles dio en la gloria

Y su espada aún se encuentra en vilo. Y nos cuenta la Biblia, sobre el caso, De siete plagas que Dios como penares Envió a Egipto como enviar un cohete. Los israelitas, sin ningún retraso, Con Moisés por delante hicieron pares Y surgió nueva frase de chisguete.

T. Joroba es como las ratas de los cuentos: se mete por un huequito y se sale por otro. Su llegada apocalíptica cayó como bomba atómica en el Taller del INS, y logró intimidar al consejo editorial para que le publicaran un libro de sonetos... ¡Otro más! El volumen fue el número cuatro de la colección Biblioteca del Taller, y llevó el nombre de Cuentos prohibidos (1995).

Su título se debe a que el autor reclama aunque se ignora con cuál de sus jorobas hace la reclamación - que se trata de los verdaderos cuentos, como los niños saben que en realidad sucedieron. Como los adultos no pueden tolerar la triste y cruda realidad, los han variado con finales felices durante siglos. Por eso, T. Joroba los publica en su versión verdadera, para deleite de todos los niños del mundo, y es por eso que están prohibidos... para mayores.

Como en todo libro de cuentos, los títulos, harto explicativos, se vuelven sugerentes resúmenes de su contenido. A continuación, y violando cuantos derechos de autor puedan existir, uno de ellos, quizá el más cruel.

El cuento de tres cerditos constructores Y un malévolo lobo

POR AQUELLO del libre albedrío

Cada cerdito construyó su casa:

El uno, de madera, por la plaza;

El segundo, de paja, por el río.

$Y$ el tercer cerdito de tal trío

Usó bloques, varilla, argamasa.

-Esta puerta el lobo no traspasa

Y su mal proceder le desafío.

El invierno se vino a destajo

Y pertinaz surgió la llovedera, Haciendo cada noche oscura y fría.

El lobo las dos casas echó abajo

Y con maña apropióse la tercera,

Mató a los cerdos y abrió carnicería.

También en el Taller del INS, el susodicho autor publicó en un suplemento de Frondas, diez décimas, aunque suene redundante.

Atendió tanto el casorio:

Cuánto invitado y ensayo:

Cuánto correr: que desmayo,

Qué adornos y qué abalorios.

Ante tal combinatorio

-que ocupó tamaño tracto-

La pobre novia, ipso facto,

Agotóse en tal manera,

Que en la luna de miel postrera

Quedó dormida en el acto

El amor y algunos entredichos (1995) fue, dolorosamente, el último crimen del que T. Joroba confesara su autoría. Se compone de treinta y nueve sonetos y un poema más breve, como corolario. El libro es el resultado de un esfuerzo conjunto con 
F. Zele, miembro del Taller del Cómic y cómplice de turno, quien hizo la portada y las ilustraciones respectivas de cada uno de los sonetos.

El libro mantiene las claves poéticas de $\mathrm{T}$. Joroba, como el lenguaje sencillo y un fino humor de doble sentido. De nuevo, el cuentista sale a flote en las historias de estos sonetos, y los eventos que describe. No hay nada que disfrute más el costarricense que el mal ajeno. T. Joroba lo sabe, porque él también lo disfruta, y hace alarde de ello. Así lo vemos en el soneto 28 , Noche fatal:

Te reprocho no más un gran resfrío: Salir sin pantalones y corriendo Sintiendo en mi talón a tu marido.

Uno de los detalles curiosos de este volumen lo encontramos en el soneto 37, Cháchara estúpida. Para todos los que han estado en contacto con el Taller del INS, uno de los episodios más emotivos fue la polémica que se dio entre Zúñiga Díaz y uno de los miembros más entrañables del grupo: Claudio Antonio Cardona Cooper. Así como Zúñiga tiene su alter ego, T. Joroba, Cardona tenía el suyo: Tocar. Amigos del alma, sus personalidades alternas se enfrascaron en una deliciosa polémica de sonetos.

Como pasa en muchos trances de la vida, la gente olvida conservar recuerdos de los instantes más trascendentales, lo cual resulta obvio, teniendo en cuenta la emoción que invade al protagonista o testigo de la historia. Aunque el Taller disfrutaba de dichos duelos verbales, a nadie se le ocurrió transcribir los poemas vertidos por aquellos hombres entrados en años, quienes normalmente asistían a las reuniones con sus poemas en hojas plegadas en los bolsillos.

Lo interesante de este soneto en particular, Cháchara estúpida, es que, aunque la polémica entre T. Joroba y Tocar ya había pasado hace algunos años, Zúñiga se decidió a incluir en este volumen uno de los poemas de aquella diatriba poética. Cuidado si no se trata del soneto que inició la polémica misma. Resulta más curioso que ninguno de los miembros de aquel entonces pueda certificarlo.

Estrambótico afán: soneto exótico Más légamo que siquis del encéfalo, Tráfago apenas de un poeta zángano. Que el prójimo sagaz brinde el diagnóstico:

Un témpano fecal con tricocéfalos.

El tono del poema remite, a no dudarlo, al estilo de uno de los poetas humorísticos más brillantes de nuestra literatura: Eduardo Calsamiglia. A pesar de la mala fama que T. Joroba insistió en arrojar sobre sí mismo, era un poeta culto y muy leído. Bueno, eso dice él. Comparemos el final del soneto 37 con la conclusión del poema Praxitélica, que Calsamiglia le dedicara a su amigo Lisímaco Chavarría:

Eres el prodigioso lapidario

Que hace del ónix cintilar fulgores...

Pero nunca te entienden los lectores

Que no tienen a mano el diccionario.

Al reconstruir la historia de la literatura costarricense, las polémicas se han dado por cuestiones ideológicas o estéticas. Un ejemplo de polémica cómica se dio a inicios del siglo XX, cuando Calsamiglia le 
dedicó su epístola Diabluras a Aquileo J. Echeverría. Se trata de un poema sobre la soltería del príncipe de las tinieblas:

¿Cómo un ser tan avisado

En cuestiones de engañar, Pudo venir a pasar

A su vez en engañado?

Aquileo le respondió a Calsamiglia con el poema Mefistofélicas:

Mas él no entra en una empresa

Que tiene tantos bemoles,

Pues si creara una diablesa

No quedaría en los peroles

Un títere con cabeza.

Resulta una lástima no poder contar con alguno de los poemas con los que Tocar participó en la polémica con T. Joroba.

En cuanto al lenguaje, T. Joroba se mantiene en la línea de sus primeros sonetos. Existe un lenguaje de uso popular, urbano y callejero, que suele encontrar resistencia, pues incomoda a los puristas. Sin embargo, su uso le ha dado fama y renombre a muchos escritores. Ténganse en cuenta a autores como Wordsworth, Byron, Joyce o Miller.

Wordsworth es el primer poeta reconocido del movimiento romántico del siglo XIX, y se caracterizó por el uso de palabras consideradas poco poéticas en su tiempo, una de las características que citan los libros de historia de la literatura sobre este poeta del lago. En sus famosos poemas sobre Lucy, usa la palabra rocks, cuando la palabra poéticamente deseable era stones, por poner un caso. Estas palabras generan una sensación de acercamiento a la realidad, y
T. Joroba es un poeta al que le gusta tener los pies sobre la tierra, y más si esa tierra es la costarricense:

Huir del Patronato y de tu hermano $\mathrm{Y}$ a ese sinsabor, la añadidura

De completar quince años en la Peni.

T. Joroba nos demuestra que no hay nada $\tan$ en serio de lo que no pueda sacarse una sonrisa. Cuánta razón tenían Boito y Verdi: L'uom é nato burlone, burlone, burlone!

Y es que, al igual que en la ópera sobre el regordete bribón creado por Shakespeare, la risa que realmente vale es la última. Y esa, querámoslo o no, le pertenece a ese escorbuto que solo vive porque... te joroba.

\section{EL NOVELISTA}

Parecía que no terminaban de reconocerse, de amarse. Tenían tanto de qué hablar. ...y hubo un pueblo de niños.

Francisco Zúñiga.

No entra en el imaginario colectivo de la crítica académica el hecho de que un autor, en el mundo moderno, sienta que ha cumplido su sueño al publicar un libro. Suele dejarse esta fantasía para la gente común que, ante ciertas circunstancias de la vida, logra escribir y publicar el suyo, solo uno y nada más. Pero no se entiende esta situación en un escritor profesional, quien se supone encauza sus habilidades y esfuerzos en escribir y publicar.

Para un escritor, llegar a ser un cuentista logrado, o un sonetista de primer orden, habría sido tocar el cielo. Pero no para Zúñiga. Quienes conocimos su biblioteca, 
pudimos atestiguar que, aunque contaba con una gran variedad de libros de cuentos, poemas, obras dramáticas y ensayísticas, la mayor parte de su voluminosa colección la constituían novelas.

Zúñiga creció con la idea tradicional de que la novela es la montaña mágica, la cumbre del quehacer creativo literario, tal y como se considera la sinfonía en la música orquestal y la ópera en la música vocal. Sus héroes personales son de sobra conocidos: Mann, Hemingway, Hugo, Joyce, Steinbeck, Fallas, Herrera García y Marín Cañas. Todos ellos novelistas. Suponemos que se sentía menos que ellos, porque no había cuajado una novela en su vastísima obra. Y aun en el caso de alguien tan humilde como Zúñiga, eso tiene que pesar.

... Y hubo un pueblo de niños (1995) fue la última gran empresa de su vida. Fueron escritos, y vieron la luz, los últimos libros de cuentos y poesía, mientras las líneas de su novela se iban escribiendo despacio. Tamuga, la Chupeta y T. Joroba se daban cita entre sus páginas y no se iban, no les daba la gana irse. La muerte apremia, y todos los personajes hacen fila delante de ella, como los fantasmas de los hijos de Banquo delante de Macbeth.

Las teclas de su máquina de escribir, tan rápidas y ágiles cuando se trataba de sonetos satíricos y cuentos memorables, parecían trabarse cuando retomaba su escritura. Las amarillentas páginas que constituían su primer borrador pocas veces se dejaron ver fuera de los muros de su casa en Barrio México, si no era porque Zúñiga las ponía sobre la mesa del Taller del INS para que Cristián Marcelo Sánchez y Toño Cardona se las llevaran a su casa para revisarlas y, luego, devolverlas con hojas adicionales para las observaciones y apuntes. Finalmente, como Gandalf buscando en Gondor los papeles que le hablaran del paso del Anillo Único por Minas Tirith, se pasó muchas horas frente a ellas, corrigiéndolas y revisándolas. Así le sugirió siempre a sus pupilos, en las sesiones de taller, que debían revisar los textos. El maestro dando ejemplo. Parecía que la novela nunca vería la luz. Quizá no estaba completamente satisfecho con el manuscrito.

Lo cierto es que en 1995, con una salud quebrantada por su enfisema pulmonar y la quimioterapia, Zúñiga publica sus tres últimos libros, de su propio bolsillo, con la ayuda de la Litografia Morales: Cuentos de patria o muerte, El amor y algunos entredichos... y también, aunque parezca un milagro, la novela. El volumen de cuentos La encerrona de la Chupeta y otros desbarajustes fue publicado un año después por la EUNED, pero dicha publicación ya estaba planteada desde finales de 1994, y se fue retrasando por asuntos de orden burocrático.

Para un escritor, publicar un texto porque siente la posibilidad de que la muerte lo alcance antes de hacerlo, debe de ser un sentimiento impresionante. Aún más terrible debe ser sentir esa premura y publicar un libro teniendo dudas. Los dos libros de cuentos y el libro de poesía fueron publicados sin temor alguno, pues ya llevaban meses listos. La novela se fue para la imprenta, prácticamente, con la tinta de las últimas correcciones aún fresca.

La novela presenta las mismas carencias señaladas en Cuentos de patria o muerte (1995). Sin embargo, la imagen lezamiana 
viene una vez más en su ayuda, lo oculta, lo cobija. El prosista sabe que no domina la novela, no le queda tiempo para hacerlo. Su trama recuerda la inmensidad de Proust o Joyce, pero con la premura y el alocamiento de Hemingway y Scott Fitzgerald. Las descripciones son estáticas, monolíticas, como suele hacerlas en sus cuentos. La acción se detiene, no avanza, se esfuma el movimiento, como en sus cuentos. Pero una novela no es un cuento.

La colilla del último cigarro muere en el centro de la calle. Se apaga y deshace. El papel del filtro se abre y muestra inocentemente sus entrañas. Las luces de los rótulos empiezan a encenderse. El reloj marca las siete.

El prosista lezamiano aparece en su mejor versión. La novela presenta algunos de los pasajes más poéticos de la narrativa de Zúñiga, y eso es un acierto, un logro de maestro. Enhorabuena, pero las escenas se suceden a cuentagotas. La acción está aprisionada, contenida. Aún en los momentos cuando puede darse su liberación y acceder a espectáculos trepidantes, el verbo acicalado y contenido nos niega el ágape definitivo.

Consideremos el reencuentro del preso, recién liberado, y su esposa. En su cuento La Ventana, Carlos Salazar Herrera se permite anunciar la pasión que se desatará, pero no la libera descaradamente. La deja contenida, otorgándole al lector la oportunidad de liberarla a su antojo. Las claves para entender sus intenciones están en los barrotes removidos y el agua fresca, símbolos de la pasión que está a punto de liberarse. Salazar no nos ofrece la pasión de los amantes porque se trata de un cuento, y uno muy íntimo, además, pero las llaves están ahí para quien desee abrir la puerta.

En la novela de Zúñiga, los guerrilleros Enrique y Lucrecia encuentran tiempo para entregarse a sus sentimientos más recónditos:

La guardia de la noche les colocó juntos y se hicieron el amor.

La montaña rebelde fue testigo de muchas cosas: valentía, arrojo, sufrimiento, desazón, victoria, muerte. Ahora lo sería del amor.

Luego, cuatro párrafos describen todos los preparativos de una boda guerrillera en medio de la selva oscura. Ante la tensión del combate, el drama social y la angustia de la muerte, ¿no podría ser aquella la última vez que los dos personajes tuviesen la esperanza de amar? Y por tanto, en cuanto a ese acto físico de amor, ¿no debía ser lo más maravilloso posible, por si la muerte no les diera una nueva oportunidad? He aquí que, en detalles como estos, se siente la premura con que la novela fue escrita.

Nótese cómo, en circunstancias semejantes, Marín Cañas dedica páginas enteras al acto de amor en el que se ve inmerso Pedro Arnáez, constituyéndose en una de las páginas eróticas más sublimes de nuestra literatura. La comparación la hacemos no en virtud del verbo, porque sabemos cuán amplia y voluptuosa era la prosa de Marín Cañas, y cuán precisa y delicada es la prosa de Zúñiga. La comparación se hace teniendo en cuenta la distensión con la cual la primera fue abordada. 
Sin la presión de la muerte encima, ...Y hubo un pueblo de niños pudo haber sido una mejor novela, una que quitara el resuello. Y, a pesar de estos lunares, es una obra que merece ser considerada y estudiada por la academia costarricense.

Un rasgo típico de Zúñiga, el cual campea por la novela, es el estudio de sus personajes. Como buen cuentista, pocas frases ocupa para derribar nuestros argumentos y abatirnos con los suyos. Ante la solidez de sus conceptos, nada puede decirse, como sucede con Gogol y Dostoyevski. Véase uno de los temas capitales de El Gran Inquisidor, sólidamente esbozado en pocas líneas:

Quienes guardan prisión - dijo - hermanos descarriados que en mala hora asesinaron, quitaron lo ajeno, tal vez concupiscentes de la carne que les llevó a vicios inconfesables, deben contar con el perdón de los hombres, puesto que Dios, con su infinita bondad, ya los había perdonado.

También el lamento que recorre las quinientas páginas de Las Uvas de la Ira, de Steinbeck, lo condensa Zúñiga en el pasaje final de su novela:
La lucha del hombre, por el hombre, para el hombre y desde el hombre. Marujita, que aún dormía, dio vuelta en su cama y llamó a su papá. De improviso, como con enojo, se descolgó un aguacero furibundo. El reloj del universo, mientras tanto, seguía caminando.

...Y hubo un pueblo de niños no es la mejor novela de la literatura costarricense. Aún así, tenemos esta certeza: muchos autores lo habrían dado todo por escribirla.

\section{Bibliografía}

Zúñiga Díaz Francisco. El soneto en la poesía costarricense. San José: Editorial Universidad de Costa Rica, 1979.

Carlos Luis Sáenz: El escritor, el educador y el revolucionario. San José: IPECA, 1991.

...Y hubo un pueblo de niños. San José: Ediciones Zúñiga y Cabal, 1995.

Cuentos de patria o muerte. San José: Litografía Morales, 1995.

El amor y algunos entredichos... San José: Litografía Morales, 1995.

La encerrona de la chupeta y otros desbarajustes. San José: EUNED, 1996. 